American Journal of Pharmaceutical Education 2019; 83 (6) Article 7030.

\title{
BRIEF
}

\section{Impact of Team Formation Method on Student Team Performance Across Multiple Courses Incorporating Team-based Learning}

\author{
Michelle Z. Farland, PharmD, ${ }^{\mathrm{a}}$ Xiaoying Feng, PhD, ${ }^{\mathrm{b}}$ Linda S. Behar-Horenstein, PhD, ${ }^{\mathrm{c}}$ Diane E. Beck, \\ PharmD ${ }^{\mathrm{a}}$ \\ ${ }^{a}$ University of Florida College of Pharmacy, Gainesville, Florida \\ ${ }^{\mathrm{b}}$ University of Florida College of Education, Gainesville, Florida \\ ${ }^{\mathrm{c}}$ University of Florida Colleges of Dentistry, Education, Veterinary Medicine, and Pharmacy, Gainesville, Florida \\ Submitted February 20, 2018; accepted May 21, 2018; published August 2019.
}

Objective. To assess the impact of forming student learning teams based on problem solving styles on team performance and student perceptions of team quality.

Methods. This was a prospective observational study involving students in the first year of a Doctor of Pharmacy degree program. Collaborative learning teams (balanced, implementer, optimizer, and random assignment) were created based on students' results on the Basadur Creative Problem Solving Profile Inventory. The teams remained in place across all courses for the first academic year, and those courses that incorporated team-based learning (TBL) were included in the study. Team performance was assessed by administering team readiness assurance tests. The quality of team interactions was assessed using the team satisfaction domain in the Comprehensive Assessment of Team Member Effectiveness (CATME) Smarter Teamwork system and the Team Performance Scale.

Results. Each of the 237 first-year pharmacy students enrolled was assigned to one of 41 teams. All teams participated in the study. A significant difference in team performance was observed in the Principles of Patient Centered Care course but not in any of the other courses. No significant differences were found in quality of team interactions.

Conclusion. Neither team performance, nor team satisfaction, nor quality of team interactions was impacted by the method of team formation that was used. Given the existing evidence and the results of this study, team formation process, regardless of method used, may have negligible influence on the performance of collaborative learning teams in courses taught using TBL.

Keywords: team-based learning, collaborative learning, team formation, team performance, team cohesion

\section{INTRODUCTION}

When forming student teams in a team-based learning (TBL) classroom, experts recommend creating heterogeneous teams. ${ }^{1}$ The hypothesis is that once teams move through Tuckman's stages of team formation (forming, storming, norming, and performing), a heterogeneous team will perform better than a homogeneous team because the team will have expanded its collective knowledge. ${ }^{2}$ Current evidence supports the use of hetero-

Corresponding Author: Michelle Z. Farland, University of Florida College of Pharmacy, 1225 Center Dr., HPNP Building, Rm. 3307, Gainesville, FL 32610-0486. Tel: 352273-6293. E-mail: mfarland@cop.ufl.edu

Note: At the time of study and manuscript submission, author Xiaoying Feng was a student at the University of Florida College of Education. She is now at Avar Consulting, Inc., Rockville, MD. geneous teams in the workplace as these teams have been able to achieve better performance. ${ }^{3}$ However, learning teams complete tasks in a different context than teams in workplace settings. The primary goal of learning teams is developing or expanding knowledge, skills, and abilities, whereas the primary goal of many teams in a workplace setting is focusing on performance results.

There are no standards for creating heterogeneous teams, nor are there accepted criteria to define either learning teams or workplace teams as being heterogeneous. If the intent of creating heterogenous teams is to expand collective knowledge, then creating teams based on prior educational experiences should be considered. However, colleges and schools of pharmacy often find it difficult to create heterogeneous teams in this manner because Doctor of Pharmacy (PharmD) students typically have had similar experiences prior to enrolling in the program (ie, they have 


\section{American Journal of Pharmaceutical Education 2019; 83 (6) Article 7030.}

completed similar coursework). Common methods used in pharmacy education to create learning teams include randomization, student self-selection, prior work experience, grade point average, gender, personality testing, race, and strength/weakness testing. ${ }^{4}$

Pociask and colleagues compared three methods of team formation in different sections of an undergraduate general education science course taught using TBL. ${ }^{5}$ Teams were formed by the instructor, student self-selection, or random assignment. Using personality, class year, and gender as the diversity criteria, the teams formed by the instructor were more diverse. However, whether teams were formed by the instructor, self-selected, or randomly selected, there were no observed statistical differences in student performance on team assignments, including on team readiness assurance tests (tRATs) and team projects.

Camiel and colleagues compared homogenous and heterogeneous teams that were formed based on academic abilities in a PharmD program. ${ }^{6}$ Students enrolled in a single course taught using TBL were placed on one of three teams based on grade point average (GPA): high GPA (cumulative GPA = 3.0-4.00), lower GPA (cumulative GPA 2.00-2.99), or mixed GPA teams. The researchers found that team performance, as measured by tRATs, was significantly different between high GPA teams and lower GPA teams. However, all teams performed well on the tRATs, with team scores ranging from $97 \%$ to $99 \%$, which made differentiations in performance difficult. The authors also reported that student perceptions of teamwork were more positive within the homogenous teams than within mixed GPA teams. Because heterogeneous teams require more time to progress through Tuckman's stages of team formation, these observations may reflect that the teams had insufficient time to evolve.

In our curriculum, teamwork requires significant reliance on problem solving. Moreover, problem solving, adopted by multiple courses in the curriculum, is the conceptual underpinning of applications used in the TBL method. Not having clear direction on the best method to form heterogeneous learning teams of students, we elected to use the Basadur Creative Problem Solving Profile Inventory (CPSP-2) for this purpose..$^{7-9}$ The CPSP-2 identifies peoples' preferred style of problem solving. Results from the CPSP-2 can be used to heighten subjects' self-awareness and provided a unique approach to forming heterogeneous teams. We hypothesized that teams that had a blend of all styles of problem solving would evolve to become better-performing teams and develop higher-quality team interactions. The purpose of this study was to assess the impact of forming student learning teams based on problem solving styles on team performance and student perceptions of team quality.

\section{METHODS}

This was a prospective observational study that included first professional year (P1) students enrolled in the PharmD program at the University of Florida in fall 2015. Prior to program orientation, students completed the CPSP-2. ${ }^{7-9}$ The CPSP-2 classifies an individual's problem-solving style among four categories (generating, conceptualizing, optimizing, implementing), and identifies the individual's preferred style, even if that is a balanced blend of all four styles. Basadur and colleagues have documented the predictive validity of the CPSP. 9

Students were first divided into groups based on each student's campus location that was determined during the admissions process (Gainesville, Jacksonville, or Orlando). Next, students at each campus were placed on one of four types of teams: balanced, which included at least one member who was dominant in each of the four styles; implementer, which included only students with implementing as their preferred style; optimizer, which included only students with optimizing as their preferred style; and random which included students who were randomly assigned to the team without regard to their problem-solving style. There were insufficient numbers of students that were categorized as generators and conceptualizers; therefore, homogenous teams of these students could not be formed. Students were informed that their teams were created based on the results from their CPSP-2 or by random assignment, but were not told which indicator was used to form their team. Students remained with the same team across all courses in the program for the 2015-2016 academic year. Every team provided informed consent to participate in the study.

As part of orientation, teams met for the first time and got to know each other. During that time, they completed a team contract to assist with setting team norms and expectations, as well as to identify a method for managing conflict when it occurred. The team contract used was based on that created by Ofstad and colleagues and modified to fit the needs of our program (available from the authors upon request). ${ }^{10}$

Courses that incorporated team-based learning as a primary active-learning method during the 2015-2016 academic year are listed in Table 1. Scores from team readiness assurance tests (tRATs) were used to assess team performance throughout the year. Each course incorporated a different number of tRATs and a varying number of items on each tRAT (range 16-30 tRAT items total per course). Scores for each tRAT were normalized to a scale of 100 possible points to simplify statistical comparisons. 


\section{American Journal of Pharmaceutical Education 2019; 83 (6) Article 7030.}

Table 1. Delivery Timeline of Courses in the First-year Curriculum

\begin{tabular}{llc}
\hline Course Title & Semester & Block \\
\hline Pharmacy and Population Health & Fall & 1 \\
Principles of Patient Centered Care & Fall & 1 \\
Pathophysiology and Patient Assessment I & Fall & 2 \\
Pathophysiology and Patient Assessment II & Spring & 3 \\
Personal and Professional Development II & Spring & 3 and 4 \\
\hline
\end{tabular}

To assist with team development and functioning, teams completed peer evaluations at four points in the academic year, which were the middle and end of the fall and spring semesters. Peer evaluations were conducted using the Comprehensive Assessment of Team Member Effectiveness (CATME) Smarter Teamwork system. ${ }^{11}$ The dimensions selected for inclusion on the peer evaluations from CATME included: contributing to the team's work, interacting with teammates, keeping the team on track, expecting quality, and having related knowledge, skills, and abilities. Each individual on the team was assessed on these dimensions. The data provided were used as exploratory variables to compare each student's self-assessment, how their peers rated them, and how the entire team was rated. We also incorporated the team satisfaction domain in CATME to assess the overall satisfaction of the team. The team satisfaction domain is a three-item tool measured on a Likert scale on which $1=$ strongly disagree and $5=$ strongly agree and has a maximum composite score of $15 .{ }^{12}$ Additionally, students completed the Team Performance Scale (TPS) at the conclusion of the spring semester to assess the quality of team interactions. ${ }^{13,14}$ Each of the 18 items on the TPS is measured using a seven-point Likert scale on which $0=$ none of the time and $6=$ all of the time. The TPS has a maximum composite score of 108. Scores from the team satisfaction domain obtained during the final peer evaluation period and the TPS were used to assess the quality of team interactions. The University of Florida institutional review board approved the study protocol.

A comprehensive analysis of the data gathered was conducted. The Kolmogorov-Smirnov test was used to assess normality of data distribution. Based on the KolmogorovSmirnov test results, tRAT scores were compared across the four groups using the Kruskal-Wallis test for nonnormally distributed data (the Principles of Patient Centered Care course and the Personal and Professional Development II course), and ANOVA for data that was normally distributed (the Pathophysiology and Patient Assessment I and II courses, the Pharmacy and Population Health course, and all courses combined). Team satisfaction scores were compared across the four groups using the Kruskal-Wallis test for non-normally distributed data (team satisfaction at the end of spring semester) or ANOVA for normally distributed data (team satisfaction at the middle of fall, end of fall, and middle of spring semesters, and the average of all data). Team Performance Scale results were normally distributed, so data were compared across the four groups using ANOVA.

\section{RESULTS}

There were 237 PharmD students enrolled in the P1 class at the University of Florida College of Pharmacy in fall 2015. The students were divided into 41 teams. The target team size was six members, but because of considerations such as campus location, actual team size ranged from four to seven members (one four-member team; nine five-member teams; 29 six-member teams, and two seven-member teams). Team distribution into the four categories studied included balanced $(n=9$; six in Gainesville; one in Jacksonville; two in Orlando), implementer ( $\mathrm{n}=9$; three on each campus), optimizer $(n=9$; three on each campus), and random assignment $(\mathrm{n}=14$; eight in Gainesville; one in Jacksonville; five in Orlando). The number of each type of team was not the same on each campus, as target enrollment for each campus is different and campus assignments were finalized prior to the administration of the CPSP-2.

Differences in team performance for each course and across all courses are listed in Table 2. A significant difference in team performance was observed in the Principles of Patient Centered Care course $(p=.002)$ but not for all other courses $(p>.05)$. The follow-up procedure for the Principles of Patient Centered Care course revealed significant differences were found between the balanced teams and randomly formed teams and between the implementer teams and randomly formed teams $(p=.002$ and $p=.001$, respectively).

The results from assessing group differences regarding team satisfaction are summarized in Table 3. Significant differences in satisfaction were not found among students based on which of the four team formation methods were used to form teams $(p>.05)$. Similarly, there were no significant differences in ratings on the TPS related to the team formation method on which their team was based $(p>.05$, Table 4$)$. Teams that were formed to be balanced had higher numerical scores on the TPS than other types of teams, though the difference was not significant.

\section{DISCUSSION}

The findings from this study demonstrated that neither team performance, nor team satisfaction, nor quality 
American Journal of Pharmaceutical Education 2019; 83 (6) Article 7030.

Table 2. Team Scores Earned on Team Readiness Assurance Tests (tRAT) ${ }^{\mathrm{a}}$ Based on Team Formation Method

\begin{tabular}{|c|c|c|c|c|c|c|}
\hline Course Title & $\begin{array}{c}\begin{array}{c}\text { Balanced } \\
(\mathrm{n}=9)\end{array} \\
\text { Mean (SD) }\end{array}$ & $\begin{array}{c}\text { Implementer } \\
(\mathrm{n}=9)\end{array}$ & $\begin{array}{c}\begin{array}{c}\text { Optimizer } \\
(\mathrm{n}=9)\end{array} \\
\text { Mean (SD) }\end{array}$ & $\begin{array}{c}\begin{array}{c}\text { Random } \\
(n=14)\end{array} \\
\text { Mean (SD) }\end{array}$ & $\begin{array}{c}\text { All Teams } \\
(n=41) \\
\text { Mean (SD) }\end{array}$ & $p$ Value \\
\hline $\begin{array}{l}\text { Pharmacy and Population } \\
\text { Health }\end{array}$ & $96.1(2.6)$ & $94.5(3.3)$ & $92.0(6.2)$ & $94.8(5.2)$ & $94.4(4.7)$ & .30 \\
\hline $\begin{array}{l}\text { Principles of Patient } \\
\text { Centered Care }\end{array}$ & $96.2(2.1)$ & $95.2(3.3)$ & $97(2.8)$ & $98.8(1.3)$ & $97.1(2.66)$ & $.002^{\mathrm{b}}$ \\
\hline $\begin{array}{l}\text { Pathophysiology and Patient } \\
\text { Assessment I }\end{array}$ & $95(5.3)$ & $91.7(6.9)$ & $93.6(3.7)$ & $92.6(5.8)$ & $93.1(5.5)$ & .63 \\
\hline $\begin{array}{l}\text { Pathophysiology and Patient } \\
\text { Assessment II }\end{array}$ & $94.9(2.5)$ & $94(3.8)$ & $93.1(4.8)$ & $96.8(2.5)$ & $94.9(3.6)$ & .075 \\
\hline $\begin{array}{l}\text { Personal and Professional } \\
\text { Development II }\end{array}$ & $97.8(1.7)$ & $97.7(1.1)$ & $97.2(1.7)$ & $98.3(1.4)$ & $97.8(1.5)$ & .41 \\
\hline All Courses Combined & $96(1.8)$ & $94.6(1.5)$ & $94.6(2.6)$ & $96.3(2.2)$ & $95.5(2.1)$ & .14 \\
\hline
\end{tabular}

a Scores were normalized to a scale of 100 possible points

${ }^{\mathrm{b}}$ Follow-up procedure identified a difference when comparing Balanced $(p=.002)$ and Implementer $(p=.001)$ teams to teams formed using other methods

of team interactions were impacted by method of team formation when assessing longitudinal collaborative learning teams enrolled in a variety of courses. Prior published work on team formation methods in TBL have focused on students working together in teams for short periods of time during a single course or experience. ${ }^{5,6}$ Therefore, one innovative feature of this study was that team performance was followed across an entire academic year among students who were enrolled in multiple courses that included content that addressed all four domains of the center for the advancement of pharmacy education 2013 educational outcomes (eg, foundational knowledge, essentials for practice and care, approach to practice and care, and personal and professional development). ${ }^{15}$ Thus, we believe that the team members' interaction was of sufficient duration for the students to progress through Tuckman's stages of team formation. The teams in our study also experienced different learning contexts in the various courses included in the study. Though there was a statistically significant difference observed in the tRAT score in one course (Principles of Pa- tient Centered Care), it was not educationally significant because the small percentage difference in grade did not reflect a notable difference in student knowledge. Furthermore, this course was completed early in the process of team development, which may reflect that the team had not yet developed agreed upon norms. However, there was another course included in this analysis that was offered at the same time (Pharmacy and Population Health) in which no differences in team performance were observed.

Previous research on the ideal characteristics of team members when forming teams focused on workplace teams rather than collaborative learning teams. Stewart conducted a meta-analysis to identify the relationships between team design features and workplace team performance. ${ }^{3}$ Team member skill and ability levels, personality traits, background and experience, team size, task meaningfulness, and intra-team cooperation correlated positively with team performance. The effect of team member heterogeneity varies based on the type of team (eg, production, project,

Table 3. Ratings of Team Satisfaction ${ }^{\mathrm{a}}$ Based on Team Formation Method

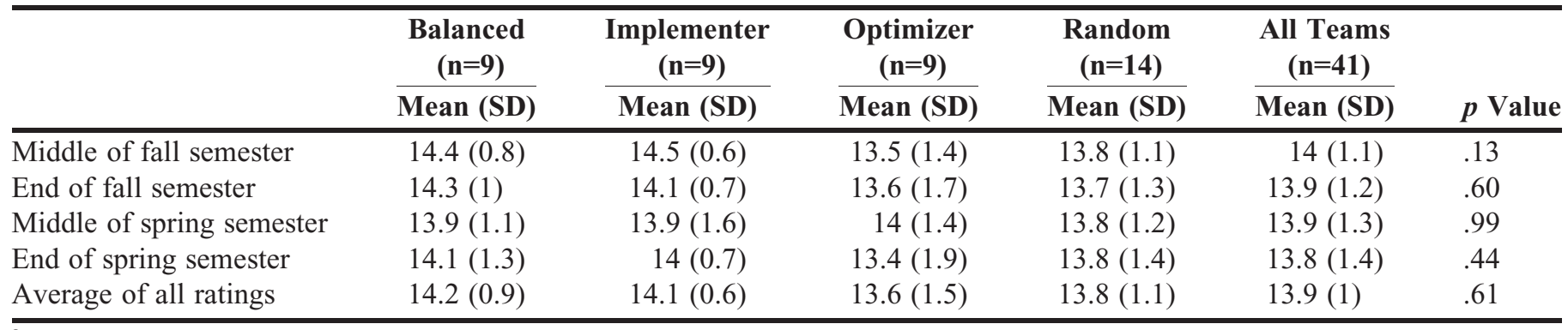

${ }^{a}$ Team satisfaction was measured with a 3-item Likert scale (score range 1-5) with maximum composite score of 15 


\section{American Journal of Pharmaceutical Education 2019; 83 (6) Article 7030.}

Table 4. Ratings of Quality of Team Interactions Measured Using the Team Performance Scale Based on Team Formation Method

\begin{tabular}{|c|c|c|c|c|c|c|}
\hline & $\begin{array}{c}\text { Balanced } \\
(\mathrm{n}=9) \\
\end{array}$ & $\begin{array}{c}\text { Implementer } \\
(n=9)\end{array}$ & $\begin{array}{c}\text { Optimizer } \\
(n=9)\end{array}$ & $\begin{array}{c}\text { Random } \\
(n=14)\end{array}$ & $\begin{array}{l}\text { All Teams } \\
(\mathrm{n}=41)\end{array}$ & \\
\hline & $\overline{\text { Mean (SD) }}$ & $\overline{\text { Mean (SD) }}$ & $\overline{\text { Mean (SD) }}$ & $\overline{\text { Mean (SD) }}$ & $\overline{\text { Mean (SD) }}$ & $p$ Value \\
\hline $\begin{array}{l}\text { Team Performance } \\
\text { Scale }^{\mathrm{a}}\end{array}$ & $99.8(7.2)$ & $95.8(7.6)$ & $94.5(12.5)$ & $93.8(12)$ & $95.7(10.2)$ & .58 \\
\hline
\end{tabular}

${ }^{a}$ Team Performance Scale was administered at the conclusion of the spring semester. It is an 18 -item tool measured on a Likert scale (score range 0-6) with maximum composite score of 108

management), with moderate, positive correlation existing for teams that require creativity, such as when solving problems. Studies assessing heterogeneity included various characteristics such as demographics (eg, age, gender, race/ethnicity), personality traits (eg, agreeableness, introversion/extroversion), or prior experiences (eg, academic performance, past work experience, education).

Current literature focused on team formation methods for courses taught using TBL are limited. ${ }^{5,6}$ Pociask and colleagues used personality traits and demographics to form diverse teams. ${ }^{5}$ However, these teams performed as well as student-selected teams and randomly formed teams. Camiel and colleagues used prior academic performance to form homogeneous and heterogeneous teams. ${ }^{6}$ Though a statistical difference was observed in team performance, the difference in scores was too small to demonstrate significant variations in student knowledge.

Espey examined factors that influence team success in an undergraduate introductory microeconomic theory course that had used TBL for 10 years and involved 114 teams. ${ }^{16}$ Teams in all courses were formed similarly by the instructor to enhance diversity on each team with respect to cumulative GPA, class (eg, freshmen), hometown location, and major. Factors influencing team success, as measured using tRAT scores, included the highest individual RAT score on the team and class diversity. Team cohesion did not significantly influence tRAT scores.

Thompson and colleagues explored factors that alter team performance among third-year medical students on a psychology rotation that incorporated TBL. They found that team cohesion and team size positively correlated with team performance. ${ }^{17}$ Van Schaik and O'Brien commented that the performance of learning teams can be impacted by heterogeneity, context of the teamwork, and the task the team is charged to complete. $^{18}$

Given the existing evidence and the results of this study, the team formation process, regardless of method used, may have negligible influence on the performance of collaborative learning teams in courses taught using TBL. While there are several methods of team formation, according to the current literature only a fraction of these methods have been explored.

There are several limitations to this study. The team formation method used may not have been the most appropriate to develop teams or to assess impact on team performance and quality of interactions. Another limitation of the study was the lack of significant variability in team performance. All of the student teams performed high on the tRATs, making it difficult to detect a difference in team performance. However, the level of performance observed in this study was consistent with that in prior reports. ${ }^{5,6}$ The team developmental stage, which had the potential to influence team performance, was also not assessed in this study. We can surmise that teams in the storming stage of team development may not perform as well as teams in the norming or performing stage. Future research should focus on identifying the factors (eg, team size, team cohesion, team longevity, task type, task context) that influence team performance in collaborative learning teams, as the majority of existing literature on team performance is focused on teams in the workplace setting.

\section{CONCLUSION}

Despite student team longevity and experience in the context of courses addressing varying content, neither team performance, nor team satisfaction, nor quality of team interactions were impacted when teams were formed using the Basadur Creative Problem Solving Profile Inventory. Given the existing evidence and the results of this study, the team formation process, regardless of method used, may have negligible influence on the performance of collaborative learning teams in courses taught using TBL.

\section{REFERENCES}

1. Michaelsen LK, Parmelee DX, McMahon KK, Levine RE. Teambased Learning for Health Professions Education. Sterling, VA: Stylus Publishing, LLC; 2008.

2. Tuckman BW. Developmental sequence in small groups. Psychol Bull. 1965;63:384-399. 


\section{American Journal of Pharmaceutical Education 2019; 83 (6) Article 7030.}

3. Stewart GL. A meta-analytic review of relationships between team design features and team performance. J Manage. 2006;32:29-54. 4. Skelley JW, Firth JM, Kendrach MG. Picking teams: student workgroup assignment methods in U.S. schools of pharmacy. Curr Pharm Teach Learn. 2015;7:745-752.

5. Pociask S, Gross D, Shih MY. Does team formation impact student performance, effort and attitudes in a college course employing collaborative learning? J Schol Teach Learn. 2017;17:19-33.

6. Camiel LD, Kostka-Rokosz M, Tataronis G. Performance and perceptions of student teams created and stratified based on academic abilities. Am J Pharm Educ. 2017;81(3):Article 47.

7. Basadur M. The Basadur simplex creative problem-solving profile inventory: development, reliability and validity. Management of Innovation and New Technology. 1998. Working paper no. 83. https:// macsphere.mcmaster.ca/handle/11375/5385. Accessed February 20, 2018. 8. Basadur M. Improving the psychometric properties of the Basadur simplex creative problem solving profile inventory. Management of Innovation and New Technology. 1998. Working paper no. 84. https://macsphere.mcmaster.ca/handle/11375/5386. Accessed February 20, 2018.

9. Basadur, MS, Gelade G, Basadur TM, et al. Testing the predictive validity of the Basadur creative problem-solving profile (CPSP). Published in the Proceedings of the Southwest Academy of Management Annual Meeting; February 2009; Oklahoma City, OK. 10. Ofstad W, Frausto S, Lowe R, Clark M. Development of a Team Contact for Team-Based Learning. Poster presented at: Annual
Meeting of the Team-Based Learning Collaborative; March 2014; Fort Worth, TX.

11. Information, CATME Smarter Teamwork. http://info.catme.org/. Accessed February 20, 2018.

12. Van der Vegt GS, Emans BJM, Van de Vuert E. Patterns of interdependence in work teams: a two-level investigation of the relations with job and team satisfaction. Pers Psychol.

2001;54:51-69.

13. Thompson BM, Levine RE, Kennedy F, et al. Evaluating the quality of learning-team processes in medical education: development and validation of a new measure. Acad Med. 2009;84(10 Suppl):S124-S127.

14. Farland MZ, Barlow PB, Lancaster TL, et al. Comparison of answer-until-correct and full-credit assessments in a team-based learning course. Am J Pharm Educ. 2015;79:Article 21.

15. Medina MS, Plaza CM, Stowe CD, et al. Center for the Advancement of Pharmacy Education 2013 educational outcomes. Am J Pharm Educ. 2013;77:Article 162.

16. Espey M. Diversity, effort, and cooperation in team-based learning. J Econ Educ. 2018;49:8-21.

17. Thompson BM, Haidet P, Borges NJ, et al. Team cohesiveness, team size and team performance in team-based learning teams. Med Educ. 2015;49:379-385.

18. van Schaik S, O'Brien B. More chickens, fewer eggs? On teambased learning, team performance and teamwork skills. Med Educ. 2015;49:348-350. 